\title{
Trigo de duplo propósito submetido ao pastejo de bovinos nos Campos Gerais do Paraná
}

\author{
Tarcísio Nicolau Bartmeyer(1), João Ricardo Dittrich(1), Hernani Alves da Silva(1), Anibal de Moraes(1), \\ Ricardo Guimarães Piazzetta(1), Tatiana Louise Gazda ${ }^{(1)}$ e Paulo César de Faccio Carvalho(2)
}

\begin{abstract}
(1)Universidade Federal do Paraná, Departamento de Fitotecnia e Fitossanitarismo, Rua dos Funcionários, no 1.540, CEP 80035-050 Curitiba, PR. E-mail: tarcisio@castrolanda.coop.br, dittrich@ufpr.br, hernani@castrolanda.coop.br, anibalm@ufpr.br, ricardo.piazzetta@agricultura. gov.br, tatiloui@brturbo.com.br (2)Universidade Federal do Rio Grande do Sul, Departamento de Plantas Forrageiras e Agrometeorologia, Caixa Postal 776, CEP 91501-970 Porto Alegre, RS. E-mail: paulocfc@ufrgs.br
\end{abstract}

Resumo - O objetivo deste trabalho foi avaliar a produtividade de grãos da cultivar de trigo de duplo propósito BRS 176 e o ganho de peso de bovinos, em função de períodos de pastejo, tendo-se considerado a intensidade de pastejo. O experimento foi realizado em Castro, PR, em Cambissolo Háplico, de maio a novembro de 2004. Utilizou-se o delineamento em blocos ao acaso, com três repetições. Os tratamentos foram constituídos de quatro períodos de pastejo: T-0, zero dia; T-15, 15 dias; T-30, 30 dias; e T-45, 45 dias. Foram utilizados novilhos com $260 \mathrm{~kg}$ de peso vivo, em pastoreio contínuo, com lotação variável e oferta diária de forragem de $8 \%$ do peso vivo animal. A produtividade de grãos foi de 3.999, 4.154, 3.210 e $1.588 \mathrm{~kg} \mathrm{ha}^{-1}$ para T-0, T-15, T-30 e T-45, respectivamente, e o ganho em peso vivo de 0, 181, 351 e $459 \mathrm{~kg} \mathrm{ha}^{-1}$. A cultivar BRS 176 apresenta alto potencial de produção de grãos sob pastejo e suporta bem a desfolha. O pastejo da cultivar BRS 176 proporciona elevado ganho de peso vivo médio diário de bovinos, e o ganho de peso por hectare aumenta linearmente com o aumento no período de pastejo.

Termos para indexação: Triticum aestivum, ganho animal, intensidade de pastejo, período de pastejo, produtividade de grãos, sistema integração lavoura-pecuária.

\section{Double purpose wheat under beef cattle grazing in Campos Gerais, Paraná State, Brazil}

\begin{abstract}
The objective of this work was to assess yield of double purpose wheat cultivar BRS 176 and cattle weight gain according to grazing periods, taking into account grazing intensity. The experiment was carried out in Castro, Paraná State, Brazil, in an Inceptisol, from May to November 2004. A completely randomized block design, with three replicates, was used. The treatments consisted of four grazing periods: T-0, zero day; T-15, 15 days; T-30, 30 days; and T-45, 45 days. Steers with $260 \mathrm{~kg}$ live weight were evaluated under continuous grazing, with variable stocking and daily forage allowance of $8 \%$ animal live weight. Grain yield was $3,999,4,154,3,210$, and $1,588 \mathrm{~kg} \mathrm{ha}^{-1}$ for T-0, T-15, T-30, and T-45, respectively, and animal weight gain was $0,181,351$, and $459 \mathrm{~kg} \mathrm{ha}^{-1}$. Cultivar BRS 176 has high grain yield potential under grazing and copes well with defoliation. Grazing on cultivar BRS 176 increases cattle average daily weight gain, and weight gain per hectare increases linearly with the increase in the grazing period.
\end{abstract}

Index terms: Triticum aestivum, animal gain, grazing intensity, grazing period, grain yield integrated crop-livestock system.

\section{Introdução}

As cultivares de trigo (Triticum aestivum L.) de duplo propósito devem ter como características principais: a elevada produção de matéria seca, a tolerância ao pastejo ou ao corte, e a elevada produtividade de grãos (Del Duca et al., 2000b). Além disso, devem apresentar ciclo apropriado que possibilite o pastejo e a colheita de grãos, com fase vegetativa longa e fase reprodutiva curta (Del Duca et al., 2000b).
Segundo Del Duca et al. (2003), a cultivar de trigo BRS 176 é apropriada para o pastejo e para a colheita de grãos, sendo recomendada para a semeadura antecipada com vistas à produção de grãos na região Centro-Sul do Paraná (região 8), onde tem apresentado produtividade média de $3.451 \mathrm{~kg} \mathrm{ha}^{-1}$ de grãos e massa de mil grãos (MMG) igual a $34 \mathrm{~g}$. Essa cultivar é considerada resistente à ferrugem do colmo e ao vírus-do-mosaico, mas suscetível a várias doenças, como ferrugem-dafolha, oídio, septoriose e vírus-do-nanismo-amarelo. 
Quanto às características tecnológicas do grão, a cultivar foi classificada como trigo brando, com uso indicado para biscoitos, confeitarias, massas, pizzas e mescla com trigo pão.

Redmon et al. (1995) citam os seguintes fatores como essenciais para obter bons resultados com o trigo de duplo propósito: fertilidade do solo adequada, semeadura na época recomendada para a região, ocorrência de precipitação adequada, ausência de pisoteio excessivo e término do período de pastejo antes da elongação dos entrenós. No manejo do trigo de duplo propósito, o corte deve ser feito quando as plantas estiverem próximas ao início da elongação do colmo, com 25 a $40 \mathrm{~cm}$ de altura, e um segundo corte pode ser realizado após 30 dias. No caso de pastejo, deve-se limitar a altura da pastagem de 5 a $7 \mathrm{~cm}$ do solo, e retirar os animais a partir do estádio de elongação do colmo (Del Duca et al., 2000b); caso contrário, o meristema apical fica exposto ao pastejo, o que reduz severamente a produtividade de grãos (Mcrea, 2003; Berges, 2005).

De acordo com Mcrae (2003), o início do período de pastejo deve ocorrer quando a planta estiver no estádio de perfilhamento, de seis a oito semanas após emergência, dependendo da variedade. Já o término do pastejo, deve ocorrer quando o meristema apical estiver abaixo do ponto de corte da ceifadeira ou do pastejo animal.

Dados sobre a produção animal em áreas com trigo de duplo propósito ainda são escassos, e há alta variação nos resultados. No geral, o pastejo do trigo de duplo propósito tem proporcionado ganhos de peso similares aos encontrados em animais alimentados com pastagens de aveia e azevém. Bortolini et al. (2004) observaram ganho de $0,950 \mathrm{~kg}$ por animal por dia e ganho de peso vivo acumulado de $127 \mathrm{~kg} \mathrm{ha}^{-1}$, em um período de 28 dias de pastejo de trigo de duplo propósito. Em 56 dias de pastejo, os autores verificaram ganho médio diário de $0,879 \mathrm{~kg}$ por animal por dia e ganho acumulado de $258 \mathrm{~kg} \mathrm{ha}^{-1}$. Em ensaios com trigo submetido a um e a dois cortes, Del Duca et al. (2000b) relataram produtividade de $3.483 \mathrm{~kg} \mathrm{ha}^{-1}$ de grãos e de $1.470 \mathrm{~kg} \mathrm{ha}^{-1}$ de matéria seca, com um corte, e de $2.104 \mathrm{~kg} \mathrm{ha}^{-1}$ de grãos e $2.506 \mathrm{~kg} \mathrm{ha}^{-1}$ de matéria seca, com dois cortes.

Embora sistemas de integração lavoura-pecuária com trigo de duplo propósito sejam viáveis, tem-se observado que a desfolha afeta diretamente a produção final de grãos. Assim, quanto mais intenso e longo for o período de pastejo, menor será a produtividade. No entanto, a maioria dos poucos protocolos experimentais que avaliaram materiais de duplo propósito não controla a intensidade de pastejo ao longo do ciclo.

O objetivo deste trabalho foi avaliar a produtividade de grãos da cultivar de trigo de duplo propósito BRS 176 e o ganho de peso de bovinos, em função de períodos de pastejo, tendo-se considerado a intensidade de pastejo.

\section{Material e Métodos}

O experimento foi conduzido no Campo Demonstrativo e Experimental, na Fazenda Capão do Cipó, coordenado pela Fundação $\mathrm{ABC}$, no Município de Castro, PR. A área experimental está localizada na região fisiográfica denominada Primeiro Planalto Paranaense, situada a $24^{\circ} 47^{\prime} 28^{\prime \prime} \mathrm{S}$ e $50^{\circ} 00^{\prime} 25^{\prime \prime} \mathrm{W}$, e a $1.005 \mathrm{~m}$ de altitude.

O clima da região, segundo a classificação de Köppen, é do tipo $\mathrm{Cfb}$, temperado com verões frescos e invernos com ocorrência de geadas severas e frequentes, sem estação seca definida (Cartas climáticas do Estado do Paraná, 1994). A média das temperaturas dos meses mais quentes é inferior a $22^{\circ} \mathrm{C}$ e a dos meses mais frios a $18^{\circ} \mathrm{C}$. A temperatura média anual varia de 17 a $18^{\circ} \mathrm{C}$ - o trimestre mais frio tem média entre 13 e $14^{\circ} \mathrm{C}$, e o mais quente entre 23 e $24^{\circ} \mathrm{C}$. A precipitação média anual varia de 1.600 a $1.700 \mathrm{~mm}$. O trimestre mais chuvoso compreende os meses de dezembro, janeiro e fevereiro, com precipitação média de 500 a $600 \mathrm{~mm}$. Já o trimestre mais seco, corresponde aos meses de junho, julho e agosto, com precipitação média de 250 a $350 \mathrm{~mm}$. O excedente hídrico varia de 500 a $800 \mathrm{~mm}$ por ano.

O solo predominante na área experimental é do tipo Cambissolo Háplico distrófico típico, Tb, relevo ondulado, epieutrófico, textura argilosa, fase campo subtropical (Levantamento semidetalhado de solos, 2001).

Foi utilizada área total de 14 ha, sendo 12 ha divididos em parcelas de 1,0 ha cada. Os 2 ha restantes foram utilizados para manutenção dos animais reguladores, quando não estavam na área experimental. A área experimental foi delimitada e dividida em parcelas com cerca elétrica, e, em todas as parcelas, havia um cocho de cimento fixo para fornecimento de sal mineralizado e um bebedouro com boia para fornecimento de água. 
Ao final de cada período de pastejo, de acordo com os tratamentos, a cultura de trigo foi conduzida para a produção de grãos.

Utilizou-se o delineamento experimental de blocos ao acaso, com quatro tratamentos e três repetições. Os tratamentos corresponderam aos períodos de pastejo da cultura do trigo: T-0, sem pastejo; T-15, 15 dias de pastejo; T-30, 30 dias de pastejo; e T-45, 45 dias de pastejo.

O experimento foi realizado de maio a novembro de 2004. Em 29 de maio, realizou-se a semeadura do trigo, e, 54 dias após a semeadura (DAS), iniciou-se o pastejo. Em 26/10/2004, aos 148 DAS, iniciou-se a colheita de grãos no tratamento sem pastejo. A colheita foi finalizada em 30/11/2004, aos 183 DAS, nas parcelas com 45 dias de pastejo.

Foram utilizados 75 bovinos machos inteiros desmamados das raças Canchim e mestiço Canchim x Angus, com peso vivo médio de $260 \mathrm{~kg}$ e idade entre nove e dez meses. Os animais, após desmama e início do experimento, ficaram 60 dias em área de pastagem. Nesse período, o rebanho foi submetido à pesagem, à vacinação contra febre aftosa, clostridioses e raiva, e ao controle de endo e ectoparasitas com ivermectina, na dose de $200 \mu \mathrm{g} \mathrm{kg}^{-1}$ de peso corporal. O padrão racial, a idade e o peso dos animais experimentais e reguladores eram semelhantes.

Todos os animais foram pesados no início do experimento, na data de entrada em pastejo, em 23/7/2004, e a cada 15 dias, até o final do experimento. A última pesagem foi realizada em 5/9/2004, o que totalizou quatro pesagens, todas feitas após jejum hídrico e alimentar de 12 horas. Durante os 45 dias de pastejo (de julho a setembro), os animais receberam água e sal mineralizado com $8 \%$ de fósforo, sem restrição.

Utilizou-se o método de pastejo de lotação contínua, com a técnica "put and take", descrita por Mott \& Lucas (1952), tendo-se mantido fixa a quantidade de cinco animais por parcela e um número variável de animais reguladores, para manter constante o nível de oferta de forragem. O ajuste da carga animal foi realizado quinzenalmente, com a entrada ou a retirada dos animais reguladores, após a avaliação da disponibilidade de matéria seca de forragem em cada parcela. Foi definido o nível de oferta diária de forragem de $8 \%$ do peso vivo animal, ou seja, $8 \mathrm{~kg}$ de matéria seca para cada $100 \mathrm{~kg}$ de peso vivo.
Nos três tratamentos com pastejo, os animais foram introduzidos na área quando a cultura atingiu massa de forragem de $1.300 \mathrm{~kg} \mathrm{ha}^{-1}$, aos 53 DAS. A oferta de forragem foi ajustada pela soma da massa de forragem com o acúmulo diário de forragem, estimado em $60 \mathrm{~kg} \mathrm{ha}^{-1}$ por dia. A oferta de forragem foi mantida nos níveis necessários para não limitar o consumo e não prejudicar o desempenho animal, conforme recomendado por Mayne et al. (2000), para possibilitar ganho de peso compatível com o potencial genético dos animais.

A estimativa de massa de forragem $\left(\mathrm{kg} \mathrm{ha}^{-1}\right)$ foi realizada em todas as parcelas antes da entrada dos animais e repetida quinzenalmente. Simultaneamente, realizou-se a avaliação da altura do pasto, com bastão graduado "sward stick" (Barthram, 1985), tendo-se feito 50 observações aleatórias por parcela.

A estimativa da matéria seca de forragem também foi realizada em todas as parcelas antes da entrada dos animais, com repetições quinzenais. Foram coletadas cinco amostras de $0,25 \mathrm{~m}^{2}$ do material vegetativo de cada parcela, com auxílio de um quadrado de ferro. Após o corte, as amostras foram identificadas, pesadas e levadas para estufa com circulação forçada de ar a $65^{\circ} \mathrm{C}$, até peso constante.

As avaliações do número de perfilhos por planta e da altura do meristema apical foram realizadas quinzenalmente, em laboratório, com 50 plantas por parcela, coletadas aleatoriamente. O número de perfilhos por planta foi obtido por meio de contagem manual. A avaliação da altura do meristema apical foi realizada com cortes longitudinais no colmo principal de cada planta, com auxílio de régua graduada, tendose medido da base do colmo (coroa) da planta até a altura em que se encontrava o meristema apical.

O ganho de peso médio diário dos animais foi obtido periodicamente pela diferença entre os pesos final e inicial dos animais "testers" dividida pelo número de dias transcorridos entre as pesagens. $\mathrm{O}$ ganho de peso vivo por hectare foi determinado pela multiplicação do ganho médio diário dos animais experimentais pela taxa de lotação por parcela e pelo número de dias que os animais permaneceram em pastejo.

O estádio de desenvolvimento da cultura (floração e ponto de colheita) foi determinado pela avaliação de 50 espigas por parcela, coletadas aleatoriamente. Considerou-se floração quando a espiga encontrava-se no estádio 64 (metade da antese completa), e o ponto 
de colheita foi definido quando os grãos estavam no estádio 87 (massa dura), segundo a escala Zadoks.

Para avaliação da produtividade de grãos de trigo, coletaram-se, manualmente, quatro unidades amostrais de $2 \mathrm{~m}^{2}$ (seis linhas de plantio com $2 \mathrm{~m}$ de comprimento) em áreas pré-marcadas, no total de $8 \mathrm{~m}^{2}$ por unidade experimental. Cada amostra foi colhida e trilhada separadamente com trilhadora mecanizada acoplada ao trator. Após a trilhagem, os grãos e o triguilho foram pesados em balança eletrônica de precisão. Em seguida, foram separadas amostras de grãos para determinação da umidade, com correção para 13\% de umidade, do peso hectolítrico (PH) e da MMG. Todas as análises foram realizadas no Laboratório de Análises da Fundação ABC. Posteriormente, foi estimada a produção média das parcelas pela média de produção de grãos obtida nas quatro áreas coletadas por parcela.

As variáveis foram avaliadas por equações de regressão linear ou quadrática. A escolha do modelo foi baseada na significância da regressão e no coeficiente de determinação $\left(\mathrm{R}^{2}\right)$. Os dados foram analisados com o procedimento GLM ("general linear models") do SAS (SAS Institute, 2000).

\section{Resultados e Discussão}

A partir da entrada dos animais em pastejo, aos 54 DAS (23 de julho), até a data de saída do último lote em pastejo, aos 99 DAS (5 de setembro), a lavoura de trigo foi considerada como pastagem.

Em todos os tratamentos com pastejo, houve redução significativa $(\mathrm{p}<0,01)$ na matéria seca de forragem, em comparação ao tratamento sem pastejo (Figura 1). Houve acúmulo de forragem quando os animais foram retirados das parcelas, conforme os tratamentos. $\mathrm{O}$ tratamento T-0 atingiu a maior produção de matéria seca no final do último período de pastejo, aos 94 dias após emergência (DAE). O T-15 apresentou rápida recuperação de matéria seca após o término do pastejo, mas não atingiu a produtividade de forragem observada no tratamento sem pastejo.

Em T-0, houve maior acúmulo de matéria seca próximo aos $80 \mathrm{DAE}$, período que coincide com o florescimento do trigo. Nos tratamentos em pastejo, após a saída dos animais das parcelas, houve a tendência de maior acúmulo de matéria seca. Em T-15, uma maior quantidade de matéria seca foi acumulada após os 80 DAE, semelhantemente a T-0. Nos tratamentos T-30 e T-45, o acúmulo foi inferior e não atingiu o pico até o florescimento. Esse atraso na recuperação das plantas pode influenciar a produtividade de grãos. Portanto, Del Duca et al. (2000a) e Mcrae (2003) recomendam evitar pastejos intensos após a elongação do colmo, em virtude da redução na velocidade de recuperação das plantas. Períodos de pastejo mais prolongados também podem afetar o desenvolvimento de raízes e reduzir as absorções de nutrientes e água, principalmente em situação de déficit hídrico, como ocorrido neste experimento.

No momento da saída dos animais do último tratamento em pastejo, a diferença de altura da pastagem entre os tratamentos T- 0 e T- 45 era de $47 \mathrm{~cm}$. A redução da altura pode evitar o acamamento de cultivares com alto potencial de crescimento; contudo, neste experimento, não foi observado acamamento em nenhum dos tratamentos. A altura do meristema apical diminuiu $32 \mathrm{~cm}$, de 56 para $24 \mathrm{~cm}$, ao se comparar os tratamentos T-0 e T-45. Isso mostra que, quando submetidas ao pastejo por períodos prolongados, as plantas de trigo de duplo propósito têm a capacidade de manter o seu meristema baixo. Assim, os animais passaram a ter acesso aos meristemas somente após 27 dias de pastejo. A remoção dos meristemas do trigo pelo pastejo ocorreu apenas no final do tratamento T-30 e durante o tratamento T-45, nos quais foram eliminados 2,3 e $37 \%$ dos meristemas, respectivamente.

Os ganhos de peso vivo médio diário nos tratamentos T-15, T-30 e T-45 foram de 1,46, 1,69 e 1,65 kg por animal por dia, respectivamente. O menor ganho de peso observado em T-15 pode ser atribuído à ausência de um período de adaptação dos animais ao experimento.

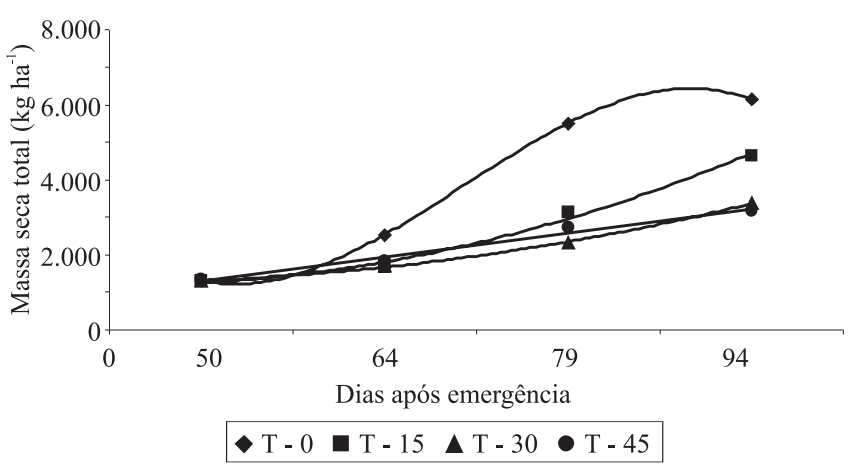

Figura 1. Produção acumulada de matéria seca da cultivar de trigo de duplo propósito BRS 176 submetida aos tratamentos: T-0, sem pastejo; T-15, 15 dias de pastejo; T-30, 30 dias de pastejo; e T-45, 45 dias de pastejo. 
É provável que o bom desempenho produtivo dos animais seja resultado da elevada oferta de forragem, $8 \%$ do peso vivo, o que permite aos animais seleção da forragem e, consequentemente, bom ganho de peso.

O ganho médio de peso vivo geral, de $1,6 \mathrm{~kg}$ por animal por dia, obtido neste trabalho, indica a alta qualidade de forragem (composição química e digestibilidade) da cultivar de trigo utilizada (Tabela 1).

$\mathrm{O}$ aumento do período de pastejo promoveu maiores ganhos de peso vivo por hectare $(p<0,01)$. Os ganhos de peso vivo por hectare nos tratamentos T-15, T-30 e T-45 foram de 181,351 e $458 \mathrm{~kg} \mathrm{ha}^{-1}$, respectivamente (Figura 2). O ganho de peso aumentou linearmente até 45 dias de pastejo. É possível que períodos maiores de pastejo no trigo aumentem o ganho de peso por hectare, entretanto, o ganho de peso diário diminuiria, pois se espera uma redução no valor nutritivo da pastagem no florescimento, em decorrência do alongamento do colmo e da formação de inflorescência.

Arzadun et al. (2003), ao avaliar diferentes pressões de pastejo em trigo de duplo propósito na Argentina, observaram ganho de peso de 283, 225 e $176 \mathrm{~kg} \mathrm{ha}^{-1}$ e produtividade de grãos de $955,1.150$ e $1.351 \mathrm{~kg} \mathrm{ha}^{-1}$, respectivamente, nas pressões de pastejo alta, média e baixa. O aumento da pressão de pastejo aumentou a produção de carne em $107 \mathrm{~kg} \mathrm{ha}^{-1}$ e reduziu a produtividade de grãos em $396 \mathrm{~kg} \mathrm{ha}^{-1}$. Os autores concluíram que a pressão de pastejo maior é economicamente favorável aos agricultores, ao considerar o preço tradicional da carne bovina em relação ao dos grãos na Argentina.

$\mathrm{O}$ número de perfilhos por planta variou significativamente $(p<0,01)$ entre os tratamentos, de acordo com o período de pastejo, e aumentou com a

Tabela 1. Proteína bruta (PB), fibra em detergente ácido (FDA), fibra em detergente neutro (FDN) e nutrientes digestíveis totais (NDT) aos 50, 65, 80 e 95 dias após emergência da cultivar de trigo de duplo propósito BRS 176 submetida a períodos de pastejo por bovinos.

\begin{tabular}{lllll}
\hline $\begin{array}{l}\text { Dias após } \\
\text { emergência }^{(1)}\end{array}$ & PB & FDA & FDN & NDT \\
\hline 50 & 33,02 & 24,17 & 45,54 & 68,09 \\
65 & 24,19 & 26,86 & 49,93 & 65,46 \\
80 & 17,60 & 30,81 & 55,44 & 60,91 \\
95 & 13,16 & 32,98 & 62,96 & 58,42 \\
\hline
\end{tabular}

(1)Aos 50 dias após emergência (DAE), ocorreu a entrada dos animais em pastejo. Os tratamentos de 15,30 e 45 dias de pastejo corresponderam, respectivamente, aos 65,80 e 95 DAE. ampliação no tempo de pastejo, de 2,8 , no T-0, para 4,5 no T-45. Provavelmente, a maior desfolha pelo pastejo e o menor número de plantas por metro quadrado proporcionou maior entrada de luz nos tratamentos com maior intensidade de pastejo e possibilitou o desenvolvimento e a manutenção de maior número de perfilhos, conforme também observado por Evans et al. (1980).

Apesar do aumento no número de perfilhos por planta, o prolongamento do período de pastejo causou redução no número de plantas por metro quadrado. Esse comportamento explica a ausência de diferença no número de espigas por metro quadrado, entre os tratamentos. Contudo, esses perfilhos não se desenvolveram adequadamente e resultaram em espigas de menor tamanho do que as produzidas por perfilhos principais, com consequente queda na produtividade de grãos (Figura 2). Houve redução da produtividade a partir de 15 dias sob pastejo, e a máxima produtividade de grãos foi observada com nove dias de pastejo. Os resultados médios para a produtividade de grãos nos tratamentos T-0, T-15, T-30 e T-45 foram de $3.999,4.154,3.210$ e $1.588 \mathrm{~kg} \mathrm{ha}^{-1}$, respectivamente.
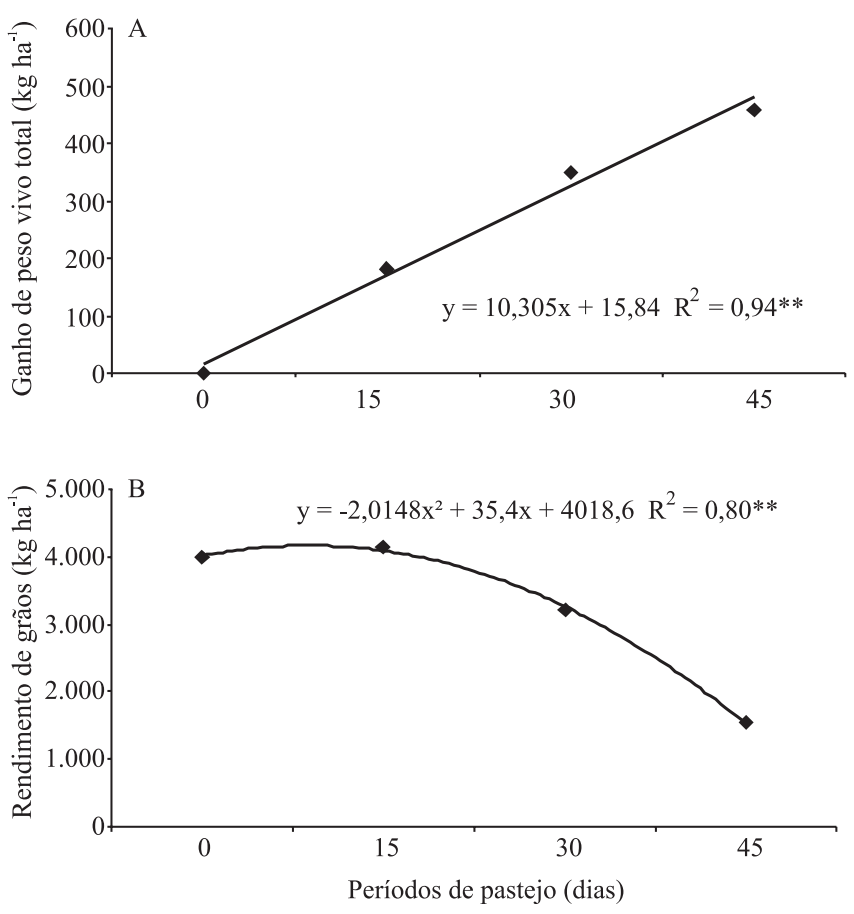

Figura 2. Ganho de peso vivo médio por hectare de bovinos (A) e produtividade média de grãos (B) em função dos períodos de pastejo da cultivar de trigo de duplo propósito BRS 176 . **Significativo a $1 \%$ de probabilidade. 
Essas produtividades são consideradas elevadas se comparadas à média regional sem pastejo no Paraná, de $2.170 \mathrm{~kg} \mathrm{ha}^{-1}$ (Governo do Paraná, 2004). Del Duca et al. (2000b) observaram produtividades de 3.451, 3.483 e $2.104 \mathrm{~kg} \mathrm{ha}^{-1}$ nos tratamentos sem corte, com um corte e com dois cortes da cultivar BRS 176, respectivamente.

$\mathrm{O} \mathrm{PH}$ e a percentagem de triguilho não foram influenciados significativamente pelos períodos de pastejo, com médias de 71,6 e 2,3\%, respectivamente.

Hossain et al. (2003), ao avaliar a data ideal para o plantio de trigo de duplo propósito, em Oklahoma, EUA, relataram aumento de $18 \%$ na produtividade de grãos com o atraso de 20 dias no plantio e redução de $68 \%$ na produção de forragem esperada. Os autores verificaram máxima produtividade de grãos, de $3.196 \mathrm{~kg} \mathrm{ha}^{-1}$, com plantio tardio, em 8 de outubro, porém, diminuição de $246 \mathrm{~kg} \mathrm{ha}^{-1}$ na produção de forragem.

De acordo com Christiansen et al. (1989), o pastejo pode aumentar a produtividade de grãos ao evitar $\mathrm{o}$ acamamento, desde que o tempo e a intensidade de pastejo não sejam severos. Outros autores também observaram que a produtividade de grãos de trigo de duplo propósito é influenciada pela época de semeadura, pela intensidade de pastejo e pelo período de pastejo (Del Duca et al., 2000a; Arzadun, 2003; Berges, 2005).

\section{Conclusões}

1. O período de pastejo de até 15 dias não afeta a produtividade de grãos da cultivar de trigo de duplo propósito BRS 176.

2. A diminuição na produtividade de grãos pelo pastejo está relacionada ao menor acúmulo de matéria seca ao final da fase vegetativa e, em períodos de pastejo maiores que 30 dias; a eliminação dos meristemas apicais também contribui para a queda de produtividade.

3. O pastejo da cultivar de trigo de duplo propósito BRS 176 proporciona elevado ganho de peso vivo médio diário de bovinos, e o ganho de peso por hectare aumenta linearmente com o aumento no período de pastejo.

4. A cultivar de trigo de duplo propósito BRS 176 apresenta elevado potencial de produção de grãos sob pastejo e grande capacidade de suportar a desfolha e de produzir forragem.

\section{Referências}

ARZADUN, M.J.; ARROQUY, J.I.; LABORDE, H.E.; BREVEDAN, R.E. Grazing pressure on beef and grain production of dual purpose wheat in Argentina. Agronomy Journal, v.95, p.1157-1162, 2003.

BARTHRAM, G.T. Experimental techniques: the HFRO sward stick. In: BARTHRAM, G.T. The hill farming research organization biennial report 1984/1985. Penicuik: HFRO, 1985. p.29-30.

BERGES, R. Trigos INIA para la próxima siembra. Revista INIA, n.2, p.14-19, 2005.

BORTOLINI, P.C.; SANDINI, I.; CARVALHO, P.C.F.; MORAES, A. de. Cereais de inverno submetidos ao corte no sistema de duplo propósito. Revista Brasileira de Zootecnia, v.33, p.45-50, 2004.

CARTAS climáticas do Estado do Paraná 1994. Londrina: IAPAR, 1994. 49p. (IAPAR. Documentos, 18).

CHRISTIANSEN, S.; SVEJCAR, T.; PHILLIPS, W.A. Spring and fall cattle grazing effects on components and total grain yield of winter wheat. Agronomy Journal, v.81, p.145-150, 1989.

DEL DUCA, L. de J.A.; ALMEIDA, J.; WOBETO, C.; DOTTO, S.R.; FRANCO, F.; MOLIN, R. Resultados da experimentação de genótipos de trigo tardios precoces no Paraná em 1998 e 1999. Passo Fundo: Embrapa Trigo, 2000a. 40p. (Embrapa Trigo. Boletim de pesquisa e desenvolvimento, 25).

DELDUCA, L. de J.A.; MOLIN, R.; SANDINI, I. Experimentação de genótipos de trigo para duplo propósito no Paraná, em 1999. Passo Fundo: Embrapa Trigo, 2000b. 28p. (Embrapa Trigo. Boletim de pesquisa e desenvolvimento, 6).

DEL DUCA, L. de J.A.; PEGORARO, D.; FONTANELI, R.S.; NASCIMENTO JÚNIOR, A. do; CUNHA, G.R. da; GUARIENTI, E.M.; COSTAMILAN, L.M.; CHAVES, M.S.; LIMA, M.I.; RODRIGUES, O. Experimentação de genótipos de trigo e outros cereais de inverno em semeadura antecipada para produção de grãos e duplo propósito no Rio Grande do Sul, em 2002. Passo Fundo: Embrapa Trigo, 2003. 25p. (Embrapa Trigo. Documentos online, 30).

EVANS, L.T.; WARDLAW, I.F.; FISCHER, R.A. Wheat. In: EVANS, L.T. (Ed.). Crop physiology. London: Cambridge University, 1980. p.101-150.

GOVERNO DO PARANÁ. Secretaria de Estado da Agricultura e do Abastecimento. Perfil da agropecuária paranaense. Curitiba: SEAB, 2003. 92p. Disponível em: <http://www.seab.pr.gov.br/ arquivos/File/PDF/revista.pdf $>$. Acesso em: 25 maio 2011.

HOSSAIN, I.; EPPLIN, F.M.; KRENZER JUNIOR, E.G. Planting date influence on dual-purpose winter wheat forage yield, grain yield, and test weight. Agronomy Journal, v.95, p.1179-1188, 2003.

LEVANTAMENTO semidetalhado de solos: município de Castro. Londrina: Embrapa Solos, 2001. 86p.

MAYNE, C.S.; WRIGHT, I.A.; FISCHER, G.E.J. Grassland management under grazing and animal response. In: HOPKINS, 
A. (Ed.). Grass: its production and utilization. $3^{\text {rd }}$ ed. Cambridge: Blackwell Science, 2000. p.247-286.

MCRAE, F. Crop agronomy and grazing management of winter cereals. NSW Agriculture, v.59, p.59-69, 2003.

MOTT, G.E.; LUCAS, H.L. The design, conduct and interpretation of grazing trials on cultivated and improved pastures. In: INTERNATIONAL GRASSLAND CONGRESS, 6., 1952, State
College. Proceedings. State College: Pennsylvania State College, 1952. p.1380-1385.

REDMON, L.A.; HORN, G.W.; KRENZER, E.G.; BERNARDO, D.J. A review of livestock grazing and wheat grain yield: boom or bust? Agronomy Journal, v.87, p.137-147, 1995.

SAS INSTITUTE. Statistical analysis system: user's guide. Versão 8.0. Cary: SAS Institute, 2000.

$\overline{\text { Recebido em } 1 \text { de agosto de } 2010 \text { e aprovado em } 20 \text { de setembro de } 2011}$ 